\title{
JUURNAL.RU
}

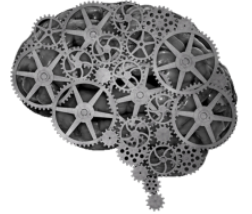

COMPANY GROUP "INTELLEKT"

Бондарь С.C. Тульский государственный университет Тула, Россия

doi: 10.18411/1j2016-3-09

\section{Морфо-функциональные взаимосвязи у пациентов с инфекциями нижних отделов респираторного тракта и их идентификация методом активной радиометрии}

Патологический процесс внутренних органов, как правило, сопровождается морфологическими изменениями и функциональными отклонениями, идентификация которых в ряде случаев существенно затруднена по причине неполноты существующих диагностических методов. В этой связи представляется важным совершенствование диагностических возможностей современной клиники, в том числе за счет привлечения новых высокоинформативных методов, способных идентифицировать слабые (субклинические) проявления патологии внутренних органов. Одним из таких методов, является активная радиометрия (АР) позволяющая оценивать активность транскапиллярного обмена воды и белка в тканях, отражающего активность тканевого метаболизма [1-3].

Целью настоящего исследования явилось изучение возможностей АР в выявлении патоморфологических и функциональных отклонений у пациентов с внебольничной пневмонией.

\section{Материалы и методы}

Всего в исследование включено 80 пациентов $\mathrm{c}$ внебольничной пневмонией (ВП) нетяжелого течения и 30 больных с острым простым бронхитом (ОБ). Группа контроля состояла из 80 практически здоровых лиц 
мужского пола, средний возраст которых составил $19 \pm 1,5$ лет. АР проводилась с помощью радиоэлектронного комплекса - «Аквафон» (регистрационное удостоверение ФСР 2010/07292) [3, 4].

Анализ результатов исследования проводился с помощью программы Statistica 6.0 компании Stat Soft.

Результаты исследования. В группе контроля средние значения ВА составили 4223,3 ед. (95\% ДИ 4123,1-4324,6 ед.), в основной группе - 5014,1 ед. (4891,3 - 5437,5 ед.). Результаты дисперсионного анализа свидетельствуют о существенных, различиях в группе контроля и основной группе $(\mathrm{p}=0,0001)$.

C целью идентификации распространенности патологических (воспалительных) изменений (очаговая, диффузная) нами был применен дискриминантный анализ, позволивший проанализировать распределение интенсивности радиосигнала по грудной клетке с целью разделения пациентов с диффузными и очаговыми инфильтративными изменениями нижних отделов респираторного тракта (рис.1). Результаты представлены в координатах первой и второй канонических линейных дискриминационных функций.

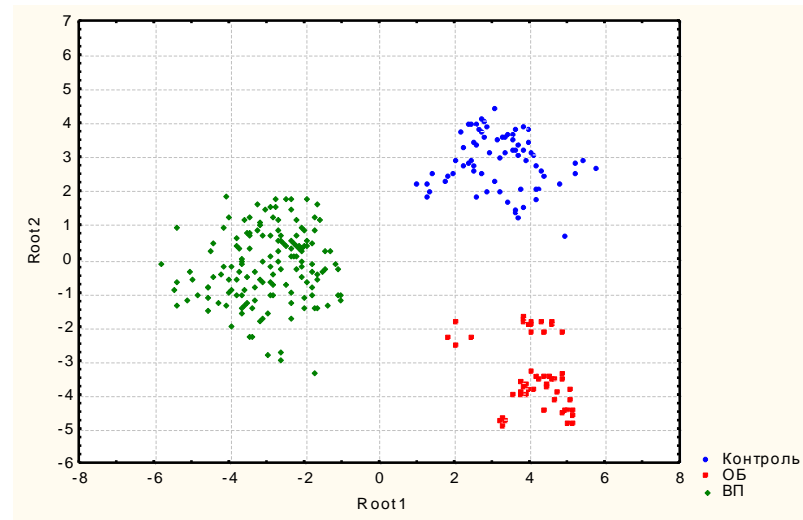

Рис.1. Результаты дискриминантного анализа

Проведенный дискриминантный анализ показал возможность разделения пациентов на группы в зависимости от особенностей распределения радиосигнала по грудной клетке. 
С целью определения чувствительности AP к функциональным проявлениям инфекционно-воспалительного процесса был проведен кросскорреляционный анализ динамического ряда РО и числа лейкоцитов периферической крови пациентов с ВП (рис.2).

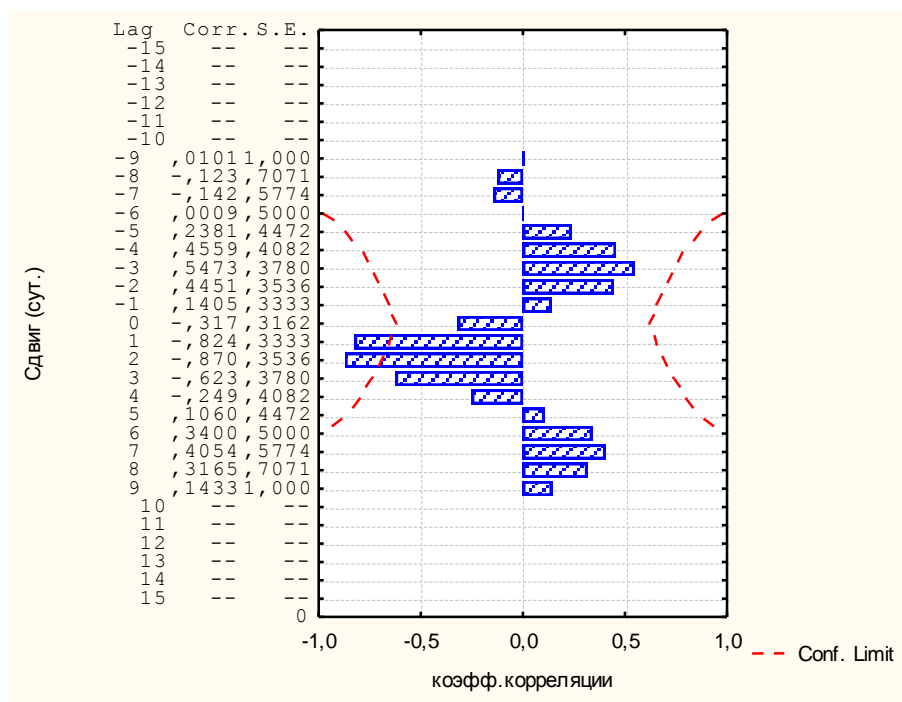

Рис.2. Кросс-корреляция ВА и числа лейкоцитов

Результаты кросскорреляционного анализа позволяют говорить о взаимосвязи динамики лейкоцитов периферической крови, являющейся интегральным показателем функционального состояния иммунной системы и BA, отражающей динамику метаболизма. При этом показатель РО опережает динамику числа лейкоцитов на 1-2 суток, о чем свидетельствует увеличение абсолютных значений коэффициента линейной корреляции двух рядов, при сдвиге динамического ряда числа лейкоцитов периферической крови по отношению РО на 2 суток вперед.

Таким образом, метод АР является чувствительным не только к изменению функционального состояния организма, но и обладает возможностью выявления морфологического субстрата патологического процесса. С учетом полученных ранее результатов, очевидно, что АР может использоваться для дифференциации патологических изменений внутренних органов воспалительной и не воспалительной природы [6-15]. 


\section{Выводы:}

1. АР является неинвазивной, безопасной и чувствительной диагностической методикой позволяющей выявлять и дифференцировать очаговые и диффузные воспалительные процессы.

2. Чувствительность АР к состоянию иммунологической реактивности позволяет обеспечивать мониторинг состояния пациента в процессе лечения с оценкой тенденций развития воспалительного процесса.

\section{Литература:}

1. Избранные технологии диагностики: Монография / В.М. Еськов и др.; под ред. А.А. Хадарцева, В.Г. Зилова, Н.А. Фудина. Тула: ООО РИФ «ИНФРА», 2008. $296 \mathrm{c}$.

2. Терехов И.В. Оценка сосудистой проницаемости с помощью активной радиометрии // Аспирантский вестник Поволжья. 2009. № 7-8. С. 187-190.

3. Исследование состояния транскапиллярного обмена и его коррекция с помощью радиоэлектронного лечебно-диагностического комплекса «Аквафон» / Громов М.С., Терехов И.В., Бондарь С.С., Дзюба М.А. и др. // Биомедицинская радиоэлектроника. 2010. № 3. С. 43-48.

4. Терехов И.В. Транс-резонансная функциональная топография в диагностике заболеваний органов дыхания (новый метод обработки информации): автореф. дисс. канд. мед. наук, Тула, 2007. 24 с.

5. Применение транс-резонансной функциональной топографии с целью оптимизации диагностической тактики у пациентов с подозрением на острый панкреатит и его осложнения / Лобаков А.И., Громов М.С., Дубовицкий С.А., Тер-Симонян Г.В., Терехов И.В. и др. // Хирург. 2008. № 8. C. 22-33. 
6. Использование радиоволнового зондирования водосодержащих сред миокарда у больных с артериальной гипертензией / Терехов И.В., Солодухин К.А., Никифоров В.С., Ломоносов А.В. // Российский кардиологический журнал. 2013. № 5 (103). С. 40-43.

7. Громов М.С., Аржников В.В., Терехов И.В. Возможности оценки функционального состояния организма с помощью собственного радиоизлучения нетепловой природы // Медицинский вестник МВД. 2008. № 5 (36). C. 38-43.

8. Возможность использования активной СВЧ-радиометрии для оценки альвеолярно-капиллярной проницаемости в эксперименте / Терехов И.В., Солодухин К.А., Аржников В.В. и др. // Регионарное кровообращение и микроциркуляция. 2011. Т. 10. № 4. С. 83-86.

9. Терехов И.В., Дзюба М.А., Наджарьян Л.С. Оценка альвеолярнокапиллярных нарушений при развитии тяжелого гемодинамического отека легких у крыс и их коррекция с помощью СВЧ-излучения // Саратовский научно-медицинский журнал. 2011. Т. 7. № 2. С. 389-392.

10. Применение метода ТРФ-топографии в диагностике воспалительных изменений нижних отделов респираторного тракта / Терехов И.В., Громов М.С., Парфенюк В.К. и др. // Саратовский научно-медицинский журнал. 2008. T. 4. № 1. C. 79-83.

11. Терехов И.В., Парфенюк В.К. Мониторинг инфильтративных процессов нижних отделов респираторного тракта у пациентов с внебольничной пневмонией методом люминесцентного анализа в радиодиапазоне // Вестник восстановительной медицины. 2009. № 3. С. 46-50.

12. Интегральная оценка воспалительного процесса у больных внебольничной пневмонией методом активной радиометрии / В.В. Аржников, В.Б. Лифшиц, В.К. Парфенюк, И.В. Терехов // Саратовский научно-медицинский журнал. 2011. Т. 7. № 4. С. 817-822. 
13. Дифференциальная диагностика заболеваний грудной клетки с помощью транс-резонансной функциональной топографии / Терехов И.В., Петросян В.И., Громов М.С., Масляков В.В. и др. // Вестник медицинского института "РЕАВИЗ": реабилитация, врач и здоровье. 2013. № 3 (11). С. 18-26.

14. Диагностика и мониторинг инфильтративных процессов в грудной полости с помощью люминисцентного излучения водосодержащих сред / Аржников В.В., Терехов И.В., Громов М.С. // Медицинский вестник МВД. 2009. № 2 (39). C. 40-46.

15. Технология динамической оценки воспалительного процесса с помощью активной резонансной радиометрии / Терехов И.В., Громов М.С., Петросян В.И., Бондарь С.С. и др. // Вестник новых медицинских технологий. 2010. Т. 17. № 1. С. 135-137. 